\title{
Presentation and Treatment of Aggressive, Triple-Negative Carcinosarcoma of the Breast
}

\author{
Niels Vizgan ${ }^{1}$, Tahereh Jokar ${ }^{2}$, Ladan Enayati ${ }^{3}$, Muhammad Salyana ${ }^{3}$, and Vladimir \\ Gotlieb $^{3}$ \\ ${ }^{1}$ Wesleyan University \\ ${ }^{2}$ St Mary's Hospital \\ ${ }^{3}$ Brookdale University Hospital and Medical Center
}

October 14, 2021

\begin{abstract}
Breast carcinosarcoma is an aggressive subtype of cancer that accounts for less than a percent of all breast malignancies. Carcinosarcoma is difficult to diagnose and treat. In the following, we present a case of breast carcinosarcoma with the treatment method.
\end{abstract}

\section{Introduction}

A rare and aggressive tumor, carcinosarcoma is a mixed, dedifferentiated carcinoma consisting of an epithelial, carcinomatous component and a non-epithelial, mesenchymal component. ${ }^{1}$ Distinct from other metaplastic carcinomas, carcinosarcoma is crucially biphasic ${ }^{5,12,17}$ lacking a clearly identifiable transition zone ${ }^{9}$ and historically has been known by several names, including biphasic metaplastic carcinoma, sarcomatoid carcinoma, and metaplastic sarcomatoid carcinoma. ${ }^{16}$

Various organs have been known to be affected by this malignancy, including the skin, breast, bladder, ovaries, lung, ${ }_{1}^{1}$ larynx,${ }^{2}$ and the uterus,${ }^{3}$ where uterine carcinosarcomas are known as malignant mixed Müllerian tumors. ${ }^{11} \mathrm{~A}$ diagnosis of carcinosarcoma in the breast typically accompanies a poor prognosis because of the tumor's propensity toward lymph, pleural, and pulmonary metastasis. ${ }^{1}$

Evidence suggests that the hybrid components of breast carcinosarcoma have a monoclonal origin ${ }^{13}$ from an original breast myoepithelial (or its precursor) cell that differentiate in a biphasic manner. ${ }^{9,}{ }^{10}$ A proteomics study by Djomehri et al. suggests that relative to non-metaplastic breast carcinomas, breast carcinosarcoma is upregulated in its epithelial-mesenchymal transition pathway and is downregulated in its oxidative phosphorylation pathway. ${ }^{14}$

In the breast, carcinosarcoma accounts for less than $0.2-1 \%$ of new cases. ${ }^{4,9,18,19}$ One oft-cited study of this malignancy demonstrated a cumulative 5-year survival rate of $49 \%$, with a precipitous decrease in survival odds at later stages of the disease. Lacking a treatment standard, ${ }^{9}$ options for remedying breast carcinosarcoma include surgical resection, chemotherapy, and radiation, ${ }^{1,7}$ although recurrence of disease has been known to occur in these approaches toward treatment. ${ }^{5}$

\section{Case Report}

56-year-old female presented to the hospital with a palpable mass $12 \mathrm{~cm}$ from the nipple. An ultrasound revealed a neoplasm in the upper inner quadrant of the left breast, with a diameter of $2.2 \mathrm{~cm}$ (Figure 1A ). Having developed within the span of a year, initial impressions of the mass were unremarkable and thought 
to be benign. EKG results for the patient were similarly unremarkable. The patient reported an unconfirmed medical history of untreated ovarian and cervical cancers, as well as fibroids.

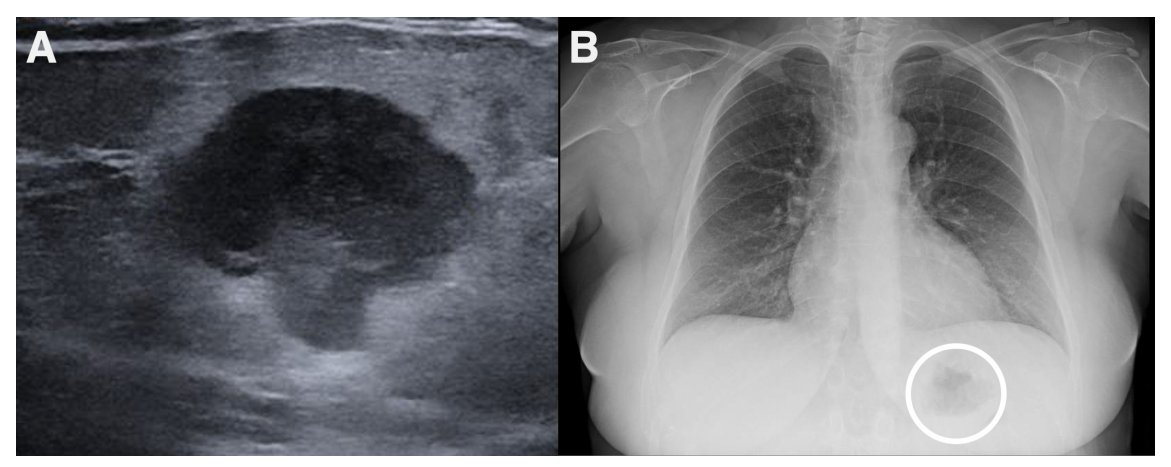

Subsequent biopsy and immunohistochemical staining on the breast mass indicated it was a malignancy negative for ER, PR, and HER2, though positive for E-cadherin and p-120 catenin. Following a chest X-Ray (Figure 1B ), as well as a lumpectomy of the mass and surrounding tissue, the malignancy was diagnosed as a ductal-type carcinoma, with troubling sarcomatous, squamous, and chondroid elements (Figures 2-5) . The tumor was an irregularly shaped, white-tan mass of ductal origin with dimensions of $3.0 \times 2.3 \times 1.7$ $\mathrm{cm}$ that had become partly necrotic and adjoined to an $8 \mathrm{~mm}$ diameter cyst. While the skin overlying the tumor and the marginal tissue surrounding the tumor were benign, positive vimentin staining confirmed that elements of the malignancy were of a mesenchymal origin. Other immunohistochemistry results indicated positive stains of AE-1, AE-3, GATA-3, P63, PD-L1, and s100, but negative stains of SMA, actin, desmin, factor XIIIa, CD34, CD68, and CD117. The cancer was shown to have greatly metastasized into the left axillary lymph node. The tumor was highly proliferative, with a Ki-67 expression of $80 \%$.

The patient, who has a medical history of anemia, was found to have depleted erythrocyte and hemoglobin levels at the time of treatment, as well as elevated platelet counts. The patient's alkaline phosphatase levels were elevated, which suggested the tumor may have metastasized into the skeletal system and caused lesions. This possibility was ruled out following PET/CT and bone scans.

\section{Discussion}

The carcinosarcoma exhibited by the patient falls into a larger umbrella category of metaplastic breast carcinomas $(\mathrm{MpBCs}){ }^{19}$ a rare type of neoplasm accounting for $0.5-3 \%$ of mammary carcinomas. ${ }^{22}$ According to WHO guidelines, MpBCs are classified as spindle cell, squamous cell, matrix-producing, carcinosarcoma, or osteoblastic, ${ }^{27}$ although they can be further described according to unique histotype. ${ }^{9,}{ }^{9,}, 20,22$ A biphasic $\mathrm{MpBC}$, carcinosarcoma contains both epithelial and sarcomatous components, ${ }^{19}$ indicated by co-expression of epithelial indicators like AE-1/3, and mesenchymal indicators like vimentin and SMA. ${ }^{22}$ Differential histological diagnoses of $\mathrm{MpBC}$ include myoepithelial carcinoma, myofibroblastic tumors, malignant phyllodes tumors, pleomorphic adenoma, and adenomyoepithelioma. ${ }^{34}$

Poorly understood and difficult to diagnose and treat, $\mathrm{MpBC}$ poses a greater risk than more common types of breast cancer. $\mathrm{MpBC}$ was not officially recognized as a distinct histological carcinoma until $2000,{ }^{28}$ which has limited research on this devastating cancer. ${ }^{22,}{ }^{29}$ Breast carcinosarcoma resembles the clinical features of invasive ductal carcinoma, ${ }^{1}$ and is often treated in a similar way, utilizing anthracycline and taxanebased regiments. ${ }^{10}$ This treatment paradigm, however, contradicts growing evidence that $\mathrm{MpBC}$ is a distinct molecular entity. ${ }^{31} \mathrm{MpBC}$ have a high incidence of a triple-negative (TN) phenotype, ${ }^{19}$ lacking receptors

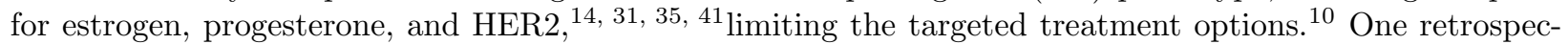
tive analysis by Xuexin et al. concluded that in TN MpBC patients, chemotherapy was not associated with improved survival. ${ }^{39}$ Large-scale studies have investigated how receptor presence impacts the survival outcomes of $\mathrm{MpBC}$ patients, although the results are contradictory. A study by Schroeder et al. found 
that HER2 positivity was correlated with greater MpBC survival than other MpBC molecular subtypes, ${ }^{36}$ but a similar study by Jinquian et al. did not find this effect. ${ }^{37} \mathrm{~A}$ study by $\mathrm{Hu}$ et al. compared patients with TN MpBCs to patients with receptor-positive MpBCs, and found that only the patients with the TN molecular subtype experienced greater survival rates after radiotherapy. ${ }^{32}$ Other researchers have found that patients with TN MpBC phenotypes have worse prognostic outcomes than non-TN MpBC patients. ${ }^{39,}{ }^{40} \mathrm{In}$ case-matched population analyses of TN MpBCs, TN MpBC patients have a more aggressive disease course and worse prognostic outcomes compared to TN non-metaplastic breast cancer patients. ${ }^{4}, 15,30,38,39,41$

The patient's breast neoplasm stained positively for GATA3, an intriguing finding considering the neoplasm's negative estrogen receptor (ER) status. GATA3, an ER-linked transcription factor, ${ }^{23,}{ }^{24,25}$ stains in high association with estrogen receptor expression. ${ }^{33}$ In studies that stain for GATA3 across distinct ER-positive mammary carcinomas, GATA3 staining reaches positivity rates between $60 \%-100 \% .{ }^{24,}{ }^{26}$ As MpBCs tend to have TN histotypes, ${ }^{31}$ the utility of GATA3 staining is mixed. Studies into the topic are often hampered by low sample sizes, but a review on the topic found that GATA3 stained ER-negative metaplastic breast carcinomas at rates between $17 \%$ and $56 \%$, depending on the study. ${ }^{24}$ In light of these difficulties, Di et al. proposed the transcription factor TRPS1 as a novel biomarker for TN MpBCs, being expressed in $86 \%$ of cases relative to GATA3's $21 \% .^{21}$

Genetic analysis of the patient's breast mass indicated mutations in $C D H 1$, raising alarm. This gene encodes E-cadherin, a transmembrane glycoprotein that maintains cell-cell adhesion. ${ }^{43}$ Germline mutations in $C D H 1$ predispose individuals to hereditary diffuse gastric cancer, ${ }^{44}$ and when these mutations are detected, patients undergo prophylactic gastrectomies. ${ }^{42,}{ }^{45}$ The patient's germ cells were genotyped, from which a CDH1 mutation was ruled out. No further procedure was necessary.

It is important to note that the tumor's initial diagnosis based on biopsy results alone suggested the mass was a ductal and lobular carcinoma, while further examination of the excised tumor revealed an identity of carcinosarcoma. This underscores the importance of proper needle placement in the biopsy site, as it is evident that diagnosing the malignancy based on tumor component alone is difficult to validate, as other studies have noted. ${ }^{10}$

The patient's tumor presented treatment challenges. Typical of other breast carcinosarcomas, ${ }^{9,}, 12$ it was a triple-negative malignancy at risk of visceral metastasis earlier rather than later in the course of disease. Because such tumors accompany poorer prognoses than receptor-positive tumors, ${ }^{6}$ the patient began an aggressive course of adjuvant chemotherapy, as well as a course of radiation at the lumpectomy site. Two years into treatment, the patient achieved remission with no sign of relapse.

Clinical studies on breast carcinosarcoma indicate that after surgery, chemotherapy combined with radiation therapy are correlated with better survival outcomes than that of either treatment alone. In one case of triple-negative breast carcinosarcoma in a 49-year-old, radiotherapy dosed at 50 Gy provided in conjunction with anthracyclines and taxanes successfully treated the disease, with no evidence of relapse in the fourth year of follow-up. ${ }^{8}$ A PR-positive case of carcinosarcoma involving a 34-year-old patient utilized a similar treatment course and had similarly positive results five years after surgery. One study matched 24 patients with metaplastic breast carcinomas to patients with non-metaplastic breast cancers of the same TNM stage, and found that with aggressive early treatment, $\mathrm{MpBC}$ patients can achieve comparable survival outcomes to patients with more typical breast carcinomas. ${ }^{10}$

\section{Conclusion}

This case report describes the presentation and treatment plan of carcinosarcoma of the breast. A rare disease, carcinosarcoma of the breast is difficult to treat and as such, clinical study and reporting of its treatment is invaluable for improving patient outcomes.

\section{Author's Contributions}

NV reviewed the literature and patient information and wrote and revised the manuscript. TOJ and LE edited the manuscript. MS provided pathology images. VG edited the manuscript and organized the project. 
All approved the final manuscript.

\section{Conflict of Interest}

The authors have no conflict of interest to declare.

\section{Consent Statement}

Patient consent has been signed and collected in accordance with the journal's patient consent policy.

\section{References}

1. Tokudome N, Sakamoto G, Sakai T, et al. A case of carcinosarcoma of the breast. Breast Cancer. 2005;12(2):149-53. doi: 10.1007/BF02966829.

2. Loh TL, Tomlinson J, Chin R, Eslick GD. Cutaneous carcinosarcoma with metastasis to the parotid gland. Case Rep Otolaryngol . 2014;2014:173235. doi: 10.1155/2014/173235.

3. Benson C, Miah AB. Uterine sarcoma - current perspectives. Int $J$ Womens Health . 2017;9:597-606. doi: 10.2147/IJWH.S117754.

4. Luini A, Aguilar M, Gatti G. et al. Metaplastic carcinoma of the breast, an unusual disease with worse prognosis: the experience of the European Institute of Oncology and review of the literature. Breast Cancer Res Treat 2007;101: 349-353. doi.org/10.1007/s10549-006-9301-1

5. Wargotz ES, Norris HJ. Metaplastic carcinomas of the breast. III. Carcinosarcoma. Cancer . 1989;64(7):1490-9. doi: 10.1002/1097-0142(19891001)64:7<1490::aid-cncr2820640722>3.0.co;2-l. PMID: 2776108 .

6. Hudis CA, Gianni L. Triple-Negative Breast Cancer: An Unmet Medical Need. The Oncologist , 2011;16:1-11. doi.org/10.1634/theoncologist.2011-S1-01

7. Kennedy WR, Gabani P, Acharya S, Thomas MA, Zoberi I. Clinical outcomes and patterns of care in the treatment of carcinosarcoma of the breast. Cancer Med . 2019;8:13791388. doi.org/10.1002/cam4.1942

8. Accurso A, Ciancia G, Della Corte GA, et al. A rare case of true carcinosarcoma of the breast. Int $J$ of Surgery Case Reports . 2016;21:125-128. doi.org/10.1016/j.ijscr.2016.03.004.

9. Kanaizumi H, Higashi C, Tanaka Y, et al. Carcinosarcoma of the breast: A case of breast conservation surgery and breast reconstruction. SAGE Open Med Case Rep . 2019;7:2050313X19853684. doi:10.1177/2050313X19853684

10. Beatty JD, Atwood M, Tickman R, Reiner M. Metaplastic breast cancer: clinical significance. Am J Surg . 2006;191(5):657-64. doi: 10.1016/j.amjsurg.2006.01.038.

11. Rajshekar SK, Guruprasad B, Shakunthala P, Rathod P, Devi U, Bafna U. Malignant mixed Mullerian tumour of the uterus.Ecancermedicalscience . 2013;7:302. doi: 10.3332/ecancer.2013.302.

12. Hennessy BT, Giordano S, Broglio K, Duan Z, Trent J, Buchholz TA, et al. Biphasic metaplastic sarcomatoid carcinoma of the breast.Annals of Oncology ; 2006;17(4):605-13. doi.org/10.1093/annonc/mdl006

13. Thompson L, Chang B, Barsky SH. Monoclonal origins of malignant mixed tumors (carcinosarcomas). Evidence for a divergent histogenesis. Am J Surg Pathol . 1996;20(3):277-85. doi: 10.1097/00000478199603000-00003.

14. Djomehri SI, Gonzalez ME, Da Veiga Leprevost F, Tekula SR, Chang H-Y, White MJ, et al. Quantitative proteomic landscape of metaplastic breast carcinoma pathological subtypes and their relationship to triple-negative tumors. Nature Communications ; 2020;11(1).

15. Nelson RA, Guye ML, Luu T, Lai LL. Survival Outcomes of Metaplastic Breast Cancer Patients: Results from a US Population-based Analysis.Annals of Surgical Oncology ; 2015;22(1):24-31.

16. Esses KM, Hagmaier RM, Blanchard SA, Lazarchick JJ, Riker AI. Carcinosarcoma of the breast: two case reports and review of the literature. Cases Journal ; 2009;2(1):15. dx.doi.org/10.1186/1757-1626$2-15$

17. Foschini MP, Dina RE, Eusebi V. Sarcomatoid neoplasms of the breast: proposed definitions for biphasic and monophasic sarcomatoid mammary carcinomas. Semin Diagn Pathol . 1993;10(2):128- 
36. PMID: 8367622 .

18. Rosai J: Special techniques in surgical pathology. Rosai and Ackerman's Surgical Pathology , Mosby Ninth edition. 2004:1810-1812

19. McCart Reed AE, Kalaw EM, Lakhani SR. An Update on the Molecular Pathology of Metaplastic Breast Cancer. Breast Cancer (Dove Med Press) . 2021;13:161-170 https://doi.org/10.2147/BCTT.S296784

20. Tse GM, Tan PH, Putti TC, Lui PC, Chaiwun B, Law BK. Metaplastic carcinoma of the breast: a clinicopathological review. J Clin Pathol . 2006;59(10):1079-1083. doi:10.1136/jcp.2005.030536

21. Ai D, Yao J, Yang F, Huo L, Chen H, Lu W, Soto LMS, Jiang M, Raso MG, Wang S, Bell D, Liu J, Wang H, Tan D, Torres-Cabala C, Gan Q, Wu Y, Albarracin C, Hung MC, Meric-Bernstam F, Wistuba II, Prieto VG, Sahin AA, Ding Q. TRPS1: a highly sensitive and specific marker for breast carcinoma, especially for triple-negative breast cancer. Mod Pathol . 2021 Apr;34(4):710-719. doi: 10.1038/s41379-020-00692-8. Epub 2020 Oct 3. PMID: 33011748.

22. Rakha EA, Coimbra ND, Hodi Z, Juneinah E, Ellis IO, Lee AH. Immunoprofile of metaplastic carcinomas of the breast.Histopathology . 2017 May;70(6):975-985. doi: 10.1111/his.13159. Epub 2017 Mar 2. PMID: 28029685.

23. Hoch RV, Thompson DA, Baker RJ, Weigel RJ. GATA-3 is expressed in association with estrogen receptor in breast cancer. Int J Cancer. 1999 Apr 20;84(2):122-8. doi: 10.1002/(sici)10970215(19990420)84:2<122::aid-ijc5>3.0.co;2-s. PMID: 10096242.

24. Asch-Kendrick R, Cimino-Mathews A. The role of GATA3 in breast carcinomas: a review. Hum Pathol . 2016 Feb;48:37-47. doi: 10.1016/j.humpath.2015.09.035. Epub 2015 Oct 28. PMID: 26772397.

25. expression in tumors and normal tissues: a useful immunomarker for breast and urothelial carcinomas. Am J Clin Pathol . 2012 Jul;138(1):57-64. doi: 10.1309/AJCP5UAFMSA9ZQBZ. PMID: 22706858.

26. Shield PW, Crouch SJ, Papadimos DJ, Walsh MD. Gata3 Immunohistochemical Staining is A Useful Marker for Metastatic Breast Carcinoma in Fine Needle Aspiration Specimens. J Cytol . 2018;35(2):9093. doi:10.4103/JOC.JOC_132_17

27. Yang F., Li J. WHO Classification of Tumors of the Breast, 2014.

28. Fritz A, Percy C, Jack A, Solin LH: In International Classification of Diseases of Oncology 3 . Geneva: World Health Organization; 2000.

29. Schwartz TL, Mogal H, Papageorgiou C, Veerapong J, Hsueh EC. Metaplastic breast cancer: histologic characteristics, prognostic factors and systemic treatment strategies. Experimental Hematology \& Oncology [Internet]. Experimental Hematology 8 Oncology . 2013;2(1):31. Available from: https://dx.doi.org/10.1186/2162-3619-2-31

30. El Zein D, Hughes M, Kumar S, et al. Metaplastic Carcinoma of the Breast Is More Aggressive Than Triple-negative Breast Cancer: A Study From a Single Institution and Review of Literature. Clin Breast Cancer . 2017;17(5):382-391. doi:10.1016/j.clbc.2017.04.009

31. Shah DR, Tseng WH, Martinez SR. Treatment options for metaplastic breast cancer. ISRN Oncol . 2012;2012:706162. doi:10.5402/2012/706162

32. Hu J, Zhang H, Dong F, et al. Metaplastic breast cancer: Treatment and prognosis by molecular subtype. Transl Oncol . 2021;14(5):101054. doi:10.1016/j.tranon.2021.101054

33. Voduc D, Cheang M, Nielsen T. GATA-3 expression in breast cancer has a strong association with estrogen receptor but lacks independent prognostic value. Cancer Epidemiol Biomarkers Prev . 2008 Feb;17(2):365-73. doi: 10.1158/1055-9965.EPI-06-1090. PMID: 18268121.

34. Yahaya J, Mremi A. Metaplastic carcinoma of breast: a report of two cases. Oxf Med Case Reports . 2020;2020(9):omaa070. Published 2020 Sep 22. doi:10.1093/omcr/omaa070

35. Bae SY, Lee SK, Koo MY, et al. The prognoses of metaplastic breast cancer patients compared to those of triple-negative breast cancer patients. Breast Cancer Research and Treatment. 2011;126(2):471-478.

36. Schroeder MC, Rastogi P, Geyer CE Jr, Miller LD, Thomas A. Early and Locally Advanced Metaplastic Breast Cancer: Presentation and Survival by Receptor Status in Surveillance, Epidemiology, and End Results (SEER) 2010-2014. Oncologist . 2018 Apr;23(4):481-488. doi: 10.1634/theoncologist.20170398. Epub 2018 Jan 12. PMID: 29330212; PMCID: PMC5896714. 
37. Mao J, Hu J, Zhang Y, Shen J, Dong F, Zhang X, Ming J, Huang T, Run X. Single Hormone ReceptorPositive Metaplastic Breast Cancer: Similar Outcome as Triple-Negative Subtype. Front Endocrinol (Lausanne) . 2021 Apr 23;12:628939. doi: 10.3389/fendo.2021.628939. PMID: 33972826; PMCID: PMC8105402.

38. Li Y, Zhang N, Zhang H, Yang Q. Comparative prognostic analysis for triple-negative breast cancer with metaplastic and invasive ductal carcinoma. J Clin Pathol . 2019 Jun;72(6):418-424. doi: 10.1136/jclinpath-2018-205544. Epub 2019 Mar 14. PMID: 30872384.

39. He X, Ji J, Dong R, Liu H, Dai X, Wang C, Esteva FJ, Yeung SJ. Prognosis in different subtypes of metaplastic breast cancer: a population-based analysis. Breast Cancer Res Treat. 2019 Jan;173(2):329341. doi: 10.1007/s10549-018-5005-6. Epub 2018 Oct 19. PMID: 30341462.

40. Hu J, Zhang H, Dong F, et al. Metaplastic breast cancer: Treatment and prognosis by molecular subtype. Transl Oncol . 2021;14(5):101054. doi:10.1016/j.tranon.2021.101054

41. Jung SY, Kim HY, Nam BH, Min SY, Lee SJ, Park C, Kwon Y, Kim EA, Ko KL, Shin KH, Lee KS, Park IH, Lee S, Kim SW, Kang HS, Ro J. Worse prognosis of metaplastic breast cancer patients than other patients with triple-negative breast cancer. Breast Cancer Res Treat. 2010 Apr;120(3):627-37. doi: 10.1007/s10549-010-0780-8. Epub 2010 Feb 9. PMID: 20143153.

42. Chun YS, Lindor NM, Smyrk TC, Petersen BT, Burgart LJ, Guilford PJ, Donohue JH. Germline Ecadherin gene mutations: is prophylactic total gastrectomy indicated? Cancer . 2001 Jul 1;92(1):181-7. doi: 10.1002/1097-0142(20010701)92:1<181::aid-cncr1307>3.0.co;2-j. PMID: 11443625.

43. van Roy F, Berx G. The cell-cell adhesion molecule E-cadherin.Cell Mol Life Sci . 2008 Nov;65(23):3756-88. doi: 10.1007/s00018-008-8281-1. PMID: 18726070.

44. Barber M, Murrell A, Ito Y, Maia AT, Hyland S, Oliveira C, Save V, Carneiro F, Paterson AL, Grehan N, Dwerryhouse S, Lao-Sirieix P, Caldas C, Fitzgerald RC. Mechanisms and sequelae of Ecadherin silencing in hereditary diffuse gastric cancer. J Pathol . 2008 Nov;216(3):295-306. doi: 10.1002/path.2426. PMID: 18788075.

45. Norton JA, Ham CM, Van Dam J, Jeffrey RB, Longacre TA, Huntsman DG, Chun N, Kurian AW, Ford JM. CDH1 truncating mutations in the E-cadherin gene: an indication for total gastrectomy to treat hereditary diffuse gastric cancer. Ann Surg . 2007 Jun;245(6):873-9. doi: 10.1097/01.sla.0000254370.29893.e4. PMID: 17522512; PMCID: PMC1876967.

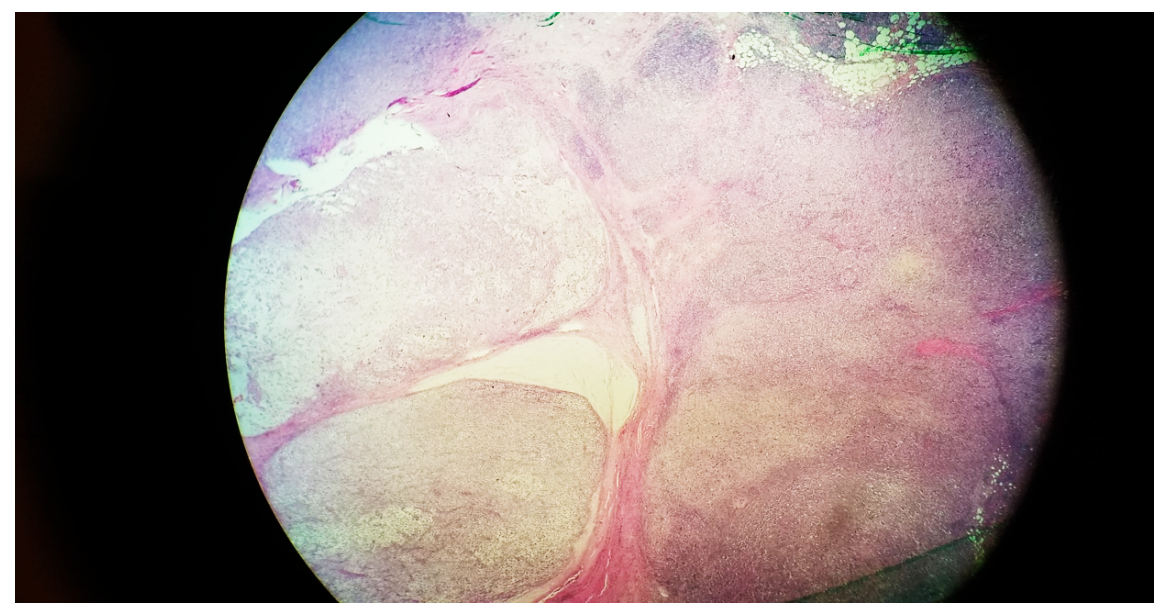

(Figure 2 ) Metaplastic carcinoma: Left side shows cartilaginous component; right side adenocarcinoma; 4X (low magnification) 


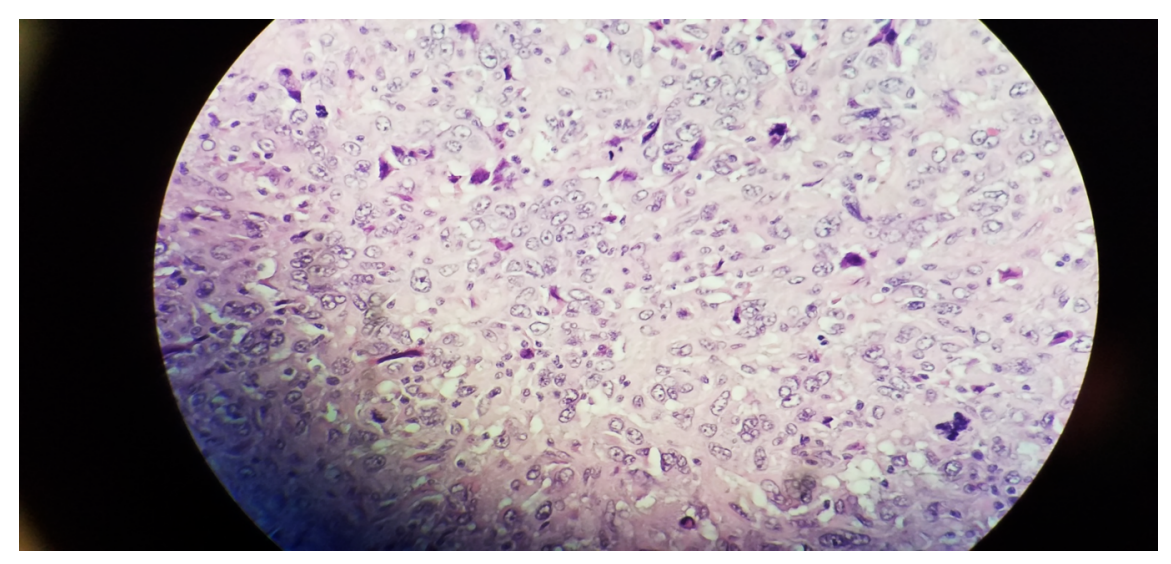

(Figure 3 ) Poorly differentiated adenocarcinoma component at 40X (high magnification)

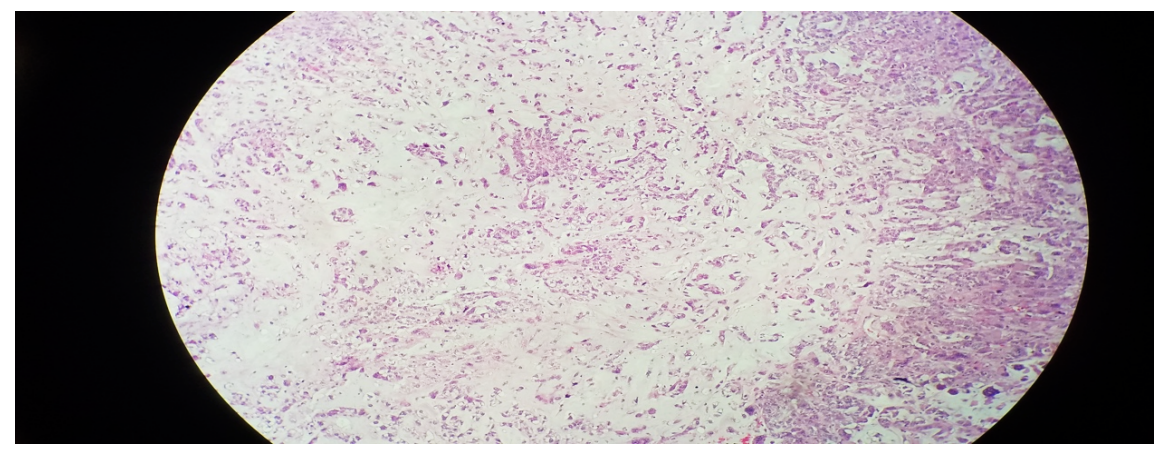

(Figure 4 ) Chondroid component at 10X (medium magnification)

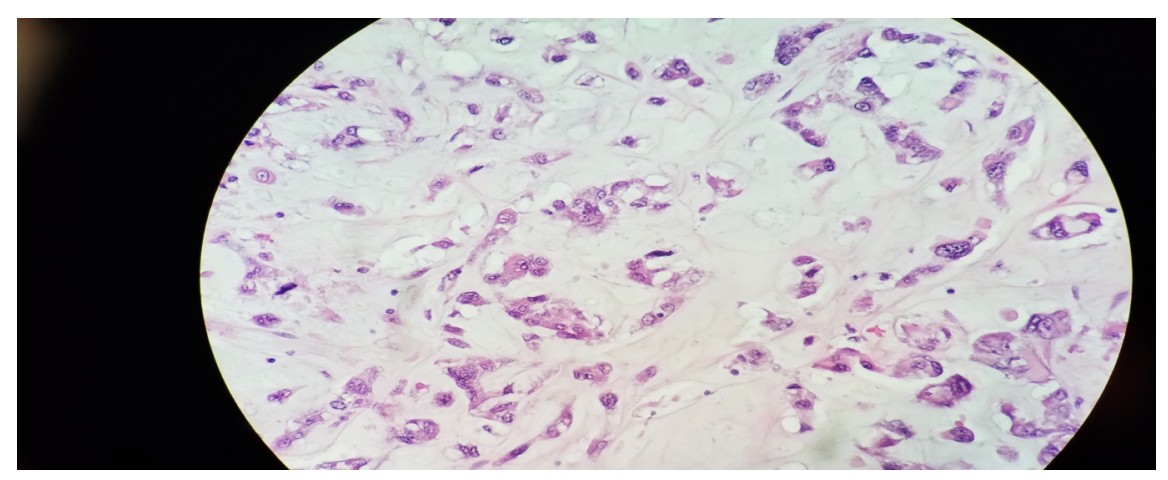

(Figure 5 ) Chondroid component at 40X (high magnification) 